\title{
Baldoceda, Ana. (2013). Aporte para la toponimia. Lima: Universidad Nacional Mayor de San Marcos.
}

Por la diversidad lingüística del Perú, donde los territorios de las diferentes lenguas colindan o se traslapan, al emprender un trabajo de descripción y explicación de topónimos es necesario entender que se tendrá que recurrir a más de una lengua nativa para discernir lo que significa un nombre de lugar.

En el trabajo Topónimos de Canta (Lima, Universidad Nacional Mayor de San Marcos, 20I3, 86 pp.), de la profesora sanmarquina Ana Baldoceda, se ha hecho frente a cierto grado de variedad para describir una muestra de topónimos de la provincia de Canta. En la Introducción del libro nos señala la procedencia del material analizado: «[...] ofrecemos tentativamente la explicación etimológica de variados topónimos del área de Canta (por cambios en la demarcación, algunos nombres de lugar, algunos nombres de lugar corresponden hoy a otras provincias, como Huaral o Huarochirí)».

Entre los topónimos explicados tenemos Acarhuay, Aguene, Allauca-Locsa, Antamaca, Carhua, Chacrajara, Condorhuachanan, Hijadero, Huillcacoto, Pallcamarca, Shongo, Taulisca, Yanahuayllani, entre otros.

Estos nombres pueden explicarse con étimos de quechua, aimara, jacaru y, también, castellano, obvio en el caso de Hijadero. En cuanto a las mencionadas lenguas nativas, debe tenerse en cuenta que los topónimos reflejan diferentes etapas de antigüedad (por ejemplo, lexemas hoy inexistentes o muy escasos en las variedades actuales), o de épocas históricas, por lo cual en la actualidad podría parecer, en determinados casos, que las significaciones asignadas no son adecuadas.

Algunos, como Acarhuay, Carhua o Shongo, tienen una sola raíz; otros, como Allauca-Locsa, Chacrajara o Pallcamarca, son de dos raíces; y algunos como Condorhuachanan son de dos raíces y estructura algo compleja. Acarhuay significa 'mariposa' (para lo cual Baldoceda cita fuente consultada); Carhua sería 'llama' (voz aimara o jacaru') u 'oro' (por metonimia, considerando que qarwa describe matices cromáticos entre amarillo y anaranjado); mientras que Shongo

1 Actualmente en jacaru el camélido peruano se denomina llama, como en quechua; pero en el Vocabulario de Belleza vemos que la antigua raíz qarwa qawra subsiste en qawr nik'i 'sebo de llama'. 
( $<$ shunqu) se explicaría como 'corazón' en quechua y como 'parte plana de ladera' (del jacaru shunku), que resultaría más apropiado para un topónimo. Sabiendo que en la zona estudiada han existido hablas de las familias quechua y aimara (sea el aimara en sí o el jacaru) que en diferentes momentos han coexistido o se han superpuesto, resulta explicable que en el análisis de varios topónimos se postulen dos étimos, coincidentes en la fonética.

Respecto de topónimos de más de una raíz, es interesante el caso de Condorhuachanan (forma original Condorhuachanani 'lugar donde ponen huevo los cóndores' > 'lugar donde nacen los cóndores'), nombre en que tenemos Cóndor $(<$ kuntur) y huachanan, que se descompone en la raíz huacha $(<$ wacha $)$ 'parir' o 'poner huevos', común al quechua y aimara, el instrumental u obligativo quechua -na y el indicador de posesión aimara $-n i$, reducido a $-n$ ). No hay ninguna duda de que el último elemento es aimara (o jacaru) porque está presente, por ejemplo, en otro topónimo analizado: Aguene (< aqhini < aqhi 'cueva' + -ni 'posesión').

Para los interesados en estudios de toponimia, es de utilidad el trabajo de Ana Baldoceda, porque resuelve con claridad la significación de los nombres de lugar.

Nora Solís

Universidad Nacional Mayor de San Marcos nsolisa@unmsm.edu.pe

\section{Trayectoria académia de la autora}

Nora Victoria Solís Aroni es magíster en Educación con mención en Docencia e Investigación en Educación Superior (UPCH), candidata al doctorado en Psicología (UNMSM), licenciada en Lingüística (UNMSM) y docente e investigadora de la Escuela Profesional de Lingüística de la UNMSM. Ha sido directora del Fondo Editorial de San Marcos (2016-2017) y coordinadora del grupo de investigación Pragmática Lingüística (2016-2019). Su área de investigación comprende diversos temas, tales como el estudio de los préstamos del inglés en el español, la influencia de la pragmática en el uso de la lengua, análisis crítico del discurso, factores psicológicos intervinientes en la adquisición de la competencia lingüística. Conferencista nacional e internacional en temas de lingüística, educación y psicología educativa.

$360 \quad$ Lengua y Sociedad. Revista de Lingüística Teórica y Aplicada 